\title{
Nerve Injury in venous procedures: Malpractice, characteristics, and strategies to avoid it
}

\author{
AL Arendt $^{1}$, FP Faccini ${ }^{1}$ \\ ${ }^{1}$ Vascular Surgery - Hospital Moinhos de Vento and Instituto de Cardiologia, Porto Alegre, Brasil
}

submitted: Nov 26, 2019, accepted: Mar 11, 2020, EPub Ahead of Print: Apr 14, 2020

Conflict of interest: None

DOI: 10.24019/jtavr.73 - Corresponding author:Dr. Ani Loize Arendt, alarendt@gmail.com

(C) 2018 Fondazione Vasculab impresa sociale ONLUS. All rights reserved.

\begin{abstract}
Nerve damage is the most important reason for malpractice claims after venous procedures. The incidence of nerve damage varies according to the technique and $4 \%$ to $23 \%$ present symptoms of nerve damage after varicose vein operations. The knowledge about nerve physiology and anatomy, proper preoperative ultrasound planning, clear communication, safe operation protocols, and good clinical records are pivotal to avoid such complications. Even so, there is no guarantee that a lesion will not occur. Nerve damage can happen with the best surgeons. The purpose of this paper is to review nerve physiology and its anatomy in relation to saphenous veins, to relate the incidence of nerve injury to each surgical technique and to outline strategies to prevent and treat this complication.
\end{abstract}

Keywords Peripheral nerve injuries, Malpractice, Varicose veins, Echo anatomy, Doppler ultrasound

\section{Introduction}

Chronic venous insufficiency (CVI) is a complex disease of high prevalence. A third of the population may present the disease and interventions to treat varicose veins are among the most common in the world according to the Edinburgh Study ${ }^{1}$.

Despite the benefits of surgical treatment for varicose veins (VV), malpractice lawsuits are becoming common in most regions of the world. Data shows that VV surgery is the most common procedure involved in claims for adverse events in vascular surgery, in both Sweden (34\%) and UK $(48 \%)^{2}$.

Campbell et $a l^{3}$ showed that nerve damage is the most common reason for malpractice claims after venous procedures, accounting for $31 \%$ of the claims. Additionally, the prevalence of nerve damage after VV operation is not low. Literature reports show that $4 \%$ to $23 \%$ of patients remain with a sensory loss after the procedure, depending on the testing method and study ${ }^{4}$.

Sam et al showed that nearly all treatment methods are accountable for nerve damage. Phlebectomies, stripping, radiofrequency and endolaser cause nerve damage and studies vary greatly concerning the incidence of this complication (from $0 \%$ to $33 \%)^{4}$.

Although knowledge about nerve anatomy is pivotal to avoid such complications, even the best surgeons can cause nerve damage. Since variation in nerve anatomic patterns are very common, high resolution ultrasonography is an important tool to visualize the nerve and to plan surgical treatment ${ }^{5}$.

The aim of this review is to review nerve physiology and its anatomy in relation to saphenous veins, discuss the importance of nerve damage in VV surgery, to evaluate the incidence of these lesions in each surgical therapeutic option and discuss strategies to prevent and treat nerve injuries. 

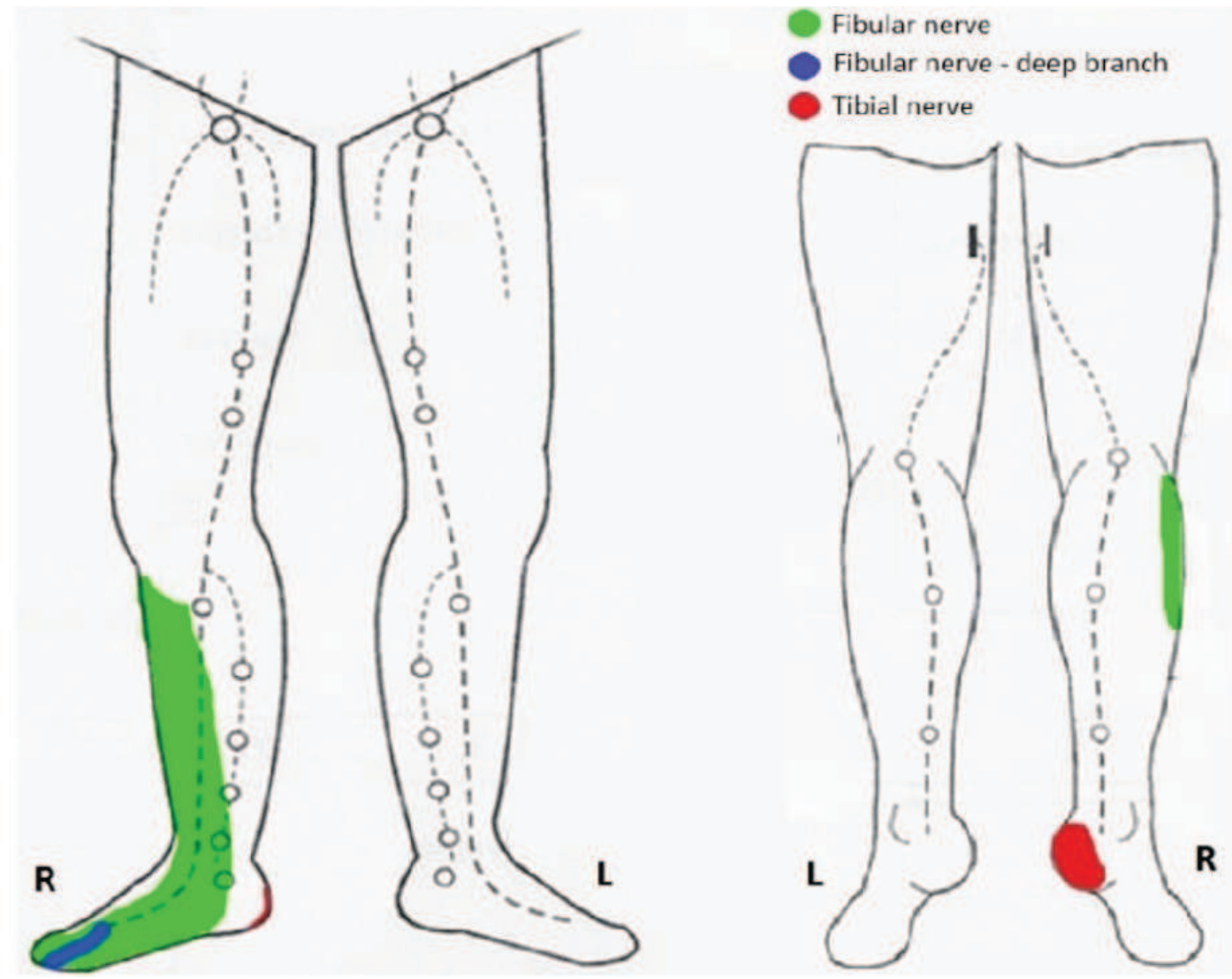

Fig 1 - Sciatic, peroneal (common fibular) and tibial nerves - cutaneous innervation.

\section{Pathophysiology}

In 1943 Seddon $^{6}$ divided nerve injuries into three categories - neuropraxia, axonotmesis, and neurotmesis.

Neuropraxia is the mildest form and presents as focal demyelination without damage to nerve continuity and without distal degeneration. It may occur after compression, traction or burning of the nerve. Usually, the complete recovery time varies from 1 week to 6 months ${ }^{7}$.

Axonotmesis is the damage to the axons with demyelination preserving connective tissue (perineurium and epineurium). Distal axon and myelin degeneration cause complete denervation but the supportive tissues allow total but slow recovery.

Neurotmesis is the most severe form of injury, it is a full anatomical and physiological transection of the nerve. In this case, there is no recovery without surgical intervention.

Venous operations cause injury mainly to the saphenous nerve, sural nerve, peroneal nerve and femoral nerve (groin reoperations mainly). The anatomy of these nerves will be briefly described.

\section{Surgical and Ultrasonographic Anatomy}

Complications and inconvenience of VV treatments may be explained by the anatomy of the lower limb veins and nerves which will be depicted in the following sections.

Variant anatomic patterns are very common. High-resolution ultrasonography permits visualization of peripheral nerves ${ }^{5}$ and a better understanding of this important matter. The tibial nerve, the common peroneal nerve and its branches, the sciatic nerve, the division of its two branches, the sural nerve and its primary branches, the saphenous nerve, the femoral nerve and the posterior cutaneous nerve of the thigh can be visualized by $\mathrm{US}^{5}$.

Ultrasonography (USG) is an excellent costeffective imaging for visualization of peripheral nerves. In cross-section, nerves usually appear as a round formation, hyperechogenic, often containing small round hypoechogenic areas. When veins are dilated, the nerve may have a slightly compressed cross-section appearing a rhomboid shape ${ }^{8}$. 

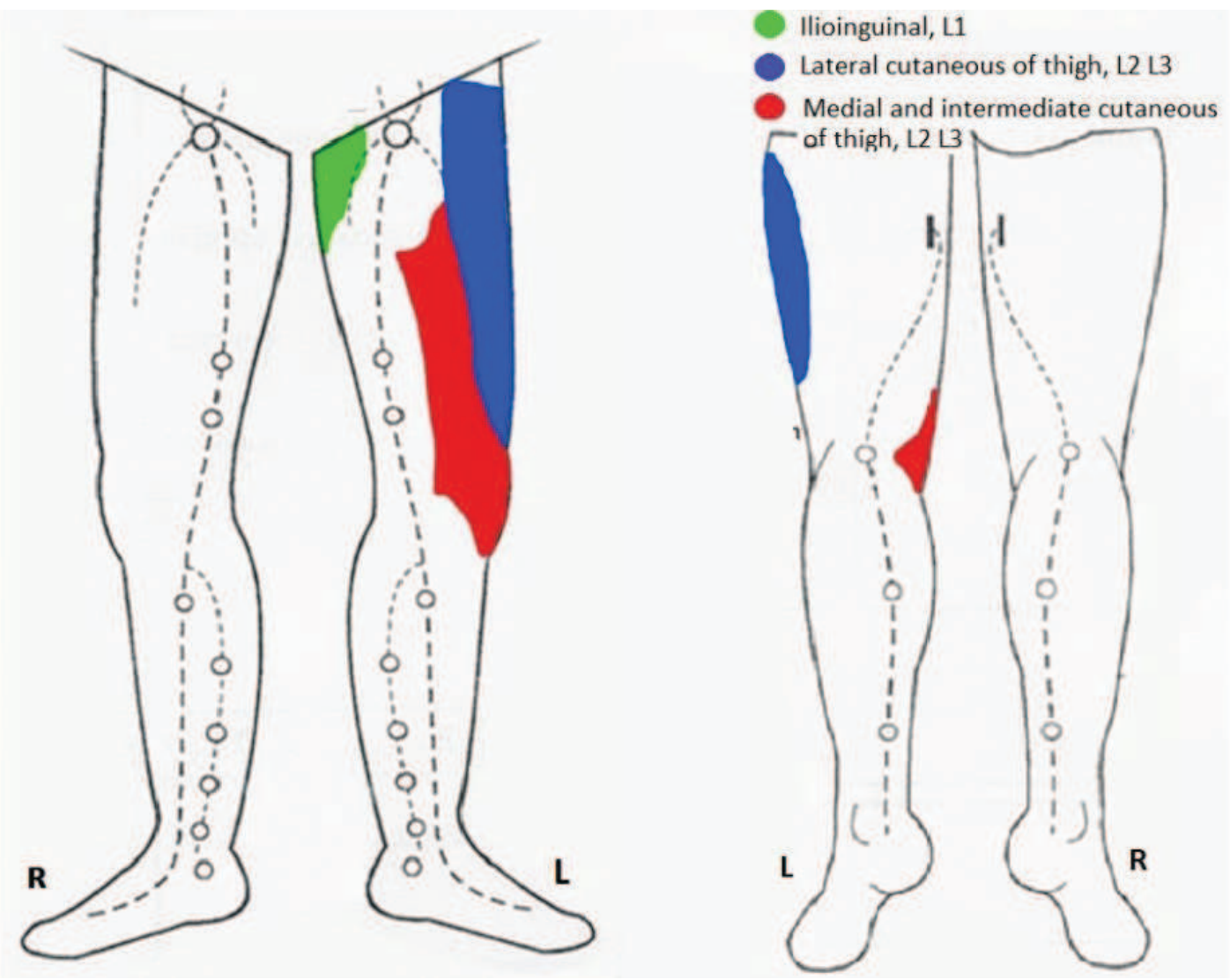

Fig 2 - Thigh nerves - cutaneous innervation.

Sciatic, peroneal (common fibular) and tibial nerves (Fig 1)

The sciatic nerve is usually formed by branches of the sacral plexus and exits the pelvis at the sciatic foramen. It runs posterior in the thigh, where it branches in peroneal (common fibular nerve) and tibial nerve. At the popliteal fossae, there are reports of damage during thermal ablation ${ }^{9}$.

The peroneal (common fibular) nerve starts when the sciatic nerve branches and travels to the anterior and lateral compartments on the leg. It may be damaged both in the popliteal fossae and in varicose vein dissection in the anterior leg ${ }^{9-11}$.

The tibial nerve is a branch of the sciatic nerve and it runs deep to the posterior compartment of the leg. The tibial nerve is not usually damaged in varicose vein surgery. A US study of the veins of the popliteal fossa in patients with SSV insufficiency revealed that $88 \%$ of the time the tibial nerve ran along the medial edge of the SSV and $4 \%$ it coursed horizontally behind the SSV or wrapped by the SSV. In a cadaver study, at the saphenopopliteal region, the average shortest distance between the SSV and the tibial nerve was $4.4 \mathrm{~mm}$; in $20 \%$ of studied patients, the distance was less than $1 \mathrm{~mm}^{9}$.

\section{Thigh Nerves}

Nerves of the thigh (Fig 2) are at risk during VV surgery. Intermediate and medial femoral-cutaneous nerves (IFCN and MFCN) originate from the femoral nerve below the inguinal ligament; some branches supply the skin as low as the front of the knee, some innervates the anterior medial thigh and some, its medial aspect. The distribution of cutaneous nerves in the thigh is important in the analysis of nerve injuries following VV surgery: in the groin and upper thigh, the ilioinguinal nerve is at risk during the initial groin dissection; in the central and distal sections of the thigh, the branches of the MFCN and IFCN are at risk ${ }^{12}$.

\section{Saphenous Nerve (SN)}

The terminal and the longest sensory branch of the femoral nerve is the saphenous nerve ${ }^{13}$ (Fig 3). In the thigh, within the femoral triangle and adductor canal, the SN lay in a deeper plane in comparison to GSV and remained separated from the vein by a considerable amount of fat, fascia, and sartorius muscle ${ }^{14}$. In the thigh, it courses subfascial and follows the superficial femoral artery ${ }^{13}$. Beyond the adductor canal, the SN passed between sartorius and gracilis muscles and became subcutaneous ${ }^{14}$. At the medial aspect of the knee and along with the upper third of the leg, SN and GSV remained separated by connective tissue sleeves of varying thickness ranging $0.5-2.5 \mathrm{~cm}$ depending on the thickness of the adipose layer. Along the middle third and lower third of leg, the SN and GSV lay in close contact, sometimes inseparably adhered to each-other. The point from where SN and GSV had an intimately related course ranged between 26 and $35 \mathrm{~cm}$ from the tip of the medial malleolus. A study recommends avoiding lower $2 / 3$ rd of the leg while harvesting saphenous venous graft to avoid damage to $\mathrm{SN}$ and subsequent neuropathy ${ }^{14}$. 
The SN also has a large number of small branches that run in an anterolateral or posterolateral direction in the middle of the lower leg. These are the medial and lateral crural cutaneous branches ${ }^{15}$. Another important anatomical relation is its neurovascular axis. The SN is accompanied until it pierces the deep fascia by the saphenous branch of the descending genicular vessels, which connected to perforators of the posterior tibial vessels ${ }^{16}$.

\section{Sural Nerve (SuN)}

Two nerve branches (tibial and peroneal) join at a variable level in the leg to form the SuN (Fig 4).

The tibial branch (medial sural cutaneous nerve, MSCN) emerges from the tibial nerve and runs parallel to the SSV in the connective tissue of the groove of the two heads of gastrocnemius, ventrally and outside the SSV compartment.

The peroneal component of the SuN (lateral sural cutaneous nerve, LSCN), arises from the common peroneal nerve (the lateral division of the sciatic nerve), descends laterally in the popliteal fossa along the border of the biceps femoris muscle, towards the peroneal head.

The tibial branch joined the peroneal branch in the middle third of the calf forming the final SuN. The SuN usually enters the SSV compartment at this level, but the exact anatomy is very variable. It lies close to the SSV. Behind the lateral malleolus, it turns anteriorly along the lateral border of the foot5.

The SSV runs behind the lateral malleolus and ascends through the middle of the calf17, to the lower portion of the popliteal fossa, where it usually reaches the popliteal vein 17 . It lies in its own fascial compartment all along its course. In the midcalf, the superficial fascial parts get much thicker upon the gastrocnemius muscle. The SSV runs between the main crural fascia and a membranous layer of the superficial fascia and this is the basis for applying tumescent anesthesia $^{18}$.

In the popliteal fossa, SSV is in close relation with the tibial nerve and the common fibular nerve. SSV lies between the medial and lateral heads of the gastrocnemius muscle, medial and close to the tibial nerve that is the medial branch of the sciatic nerve ${ }^{17}$.

Studies of the lower limb demonstrate that whereas the GSV is intimately associated with the saphenous nerve17 the SSV courses closely with the sural nerve. In a US study, the sural nerve was found to be within $5 \mathrm{~mm}$ of the SSV in $90 \%$ of cases ${ }^{9}$.

About the anatomy of the vein of Giacomini and surrounding neural structures, there are no detailed studies ${ }^{9}$.

\section{Symptoms of superficial nerve injury}

Injuries to the saphenous nerve are uniformly manifested as sensory deficits (decreased sensation, paresthesias, and dysesthesias, in decreasing order of frequency) in the anteromedial aspect of the calf to the level of the ankle. There are no motor deficits associated with saphenous nerve injury ${ }^{19}$.

The sural nerve supplies the skin of the lower half of the posterior surface of the leg, the lateral part of the dorsum of the foot, and the lateral side of the little toe. Sural neuropathy is presented with symptoms of pain, paresthesia, or numbness in the distribution of the sural nerve ${ }^{4}$.

The lesion of sciatic and peroneal nerves causes motor impairment and there are reports of drop foot after varicose vein surgery 9,10 . The peroneal (common fibular) nerve has several reports of damage in venous procedures911 , which can result in loss of foot eversion, pain and paresthesia over the majority of the dorsum of the foot and the anterolateral aspect of the lower leg. Fortunately, the damage to these nerves is rare, but it can lead to severe motor sequelae $e^{9,10}$.

Tibial nerve lesion results in loss of plantar flexion, loss of flexion of toes and weakened inversion.

\section{Peculiarities of available techniques concerning nerve injury}

\section{Sclerotherapy}

Sclerotherapy is a common procedure and the incidence of nerve damage is very low. Cavezzi et $a l^{20}$ reviewed the complications of sclerotherapy and found a $0.2 \%$ incidence of nerve injury.

Nerve damage has been described in patients undergoing sclerotherapy both in the initial procedure and in the drainage of post sclerosis hematoma21. The authors considered the most probable causes of these damages to be direct transection of the nerve by a needle and perivenous inflammation. Another possible pathophysiology of the injury is inadvertently injecting a sclerosing agent in the nerve or nerve vasculature. All the cases of nerve damage after sclerotherapy had uneventful procedures described by the doctor performing the procedure.

\section{Vein ligation and stripping $(L \& S)$}

The stripping procedure consists of vein removal using mechanical traction of the vein. Avulsion can damage surrounding nerves and cause paresthesia or even chronic aesthetic symptoms.

After saphenous vein stripping, saphenous nerve injury is reported at rates from $27 \% 22$ to $40 \%{ }^{23,19}$ based on subjective patient reports, but with neurologic testing, the rate is found to be much higher $(58 \%)^{23}$. Even mini phlebectomy can make a patient suffer from a sensory deficit $^{24}$.

Stripping below the knee increases the incidence of paraesthesia, due to the saphenous vein proximity to the nerves distally. This is due to the fact that the saphenous vein proximates the nerves progressing distally. Despite the risk of recurrence, the incidence of nerve injury decreases from $23 \%-40 \%$ to $5 \%$, when selective preservation of the saphenous vein is performed. The technique of invaginated stripping can reduce the incidence of nerve injury to $1,5 \%{ }^{24}$. 
Comparative trials for the treatment of SSV are lacking as of today and literature remains heterogeneous regarding techniques and treatment protocols. A systematic review and meta-analysis from 2015 demonstrated paresthesia in $19.6 \%$ of patients after SSV incompetence surgery ${ }^{25}$. Saphenous invagination, in theory, would be damage-free but the practical use of this technique shows no significant advantages to other techniques ${ }^{26}$.

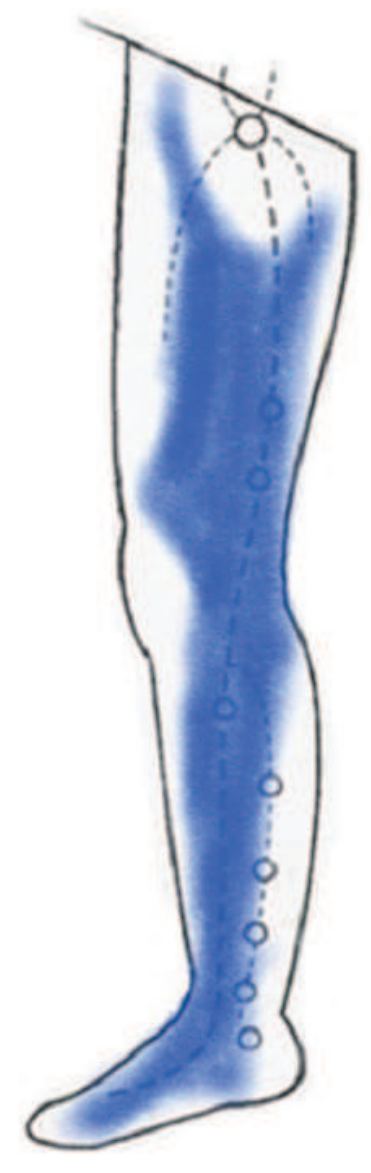

Fig 3 - Saphenous nerve - cutaneous innervation.

\section{Thermal Methods}

\section{Radiofrequency (RFA)}

Radiofrequency ablation (RFA) of the saphenous veins causes the burning of the vein to produce vein closure and the expected results. But thermal damage to superficial nerves is a known complication in this technique. It is believed that the mechanism of neural injury is incurred through thermal effects radiating from the ablated venous segment into the surrounding structures ${ }^{9}$.

With longer monitoring, a prospective study published in 2011 compared the results of different methods of RFA. Six patients $(13.9 \%)$ reported saphenous nerve paresthesia on the 10th postoperative day; after three months, paresthesia disappeared in all but 2 patients from RFA group ${ }^{32}$.
Concerning saphenous stripping, studies showed no differences between the upwards or downwards technique. We consider that partial stripping has anatomical advantages concerning nerve damage, but data suggesting real advantage is not based on large nor multiple studies and further evaluation is needed to corroborate possible advantages ${ }^{27-31}$.

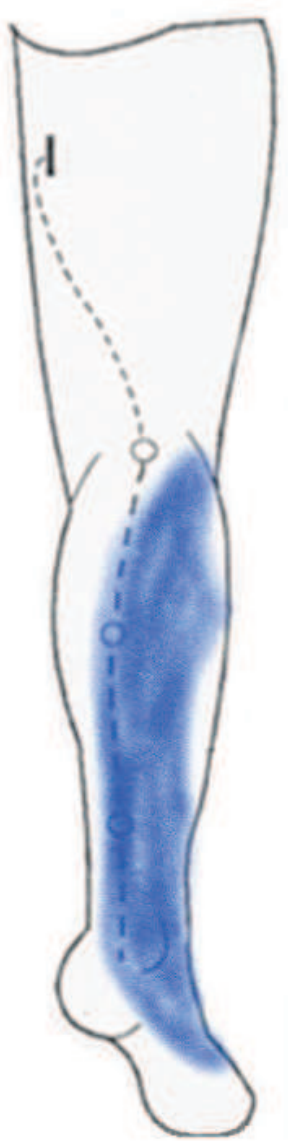

Fig 4 - Sural nerve - cutaneous innervation.

Comparing with saphenous stripping, RFA presents a lower risk of nerve damage in the vast majority of studies ${ }^{33}$. But the incidence of paresthesia rates was higher after RFA (26\%) compared to high ligation and stripping in a Korean retrospective review ${ }^{34}$.

Shahid et al reported a case of multifocal neural injury to the distal sciatic, tibial and peroneal nerves resulting in significant morbidity after RFA of the SSV in a 42-year-old woman, who had complete neurolysis of the sural, tibial, peroneal, and distal sciatic nerve after surgery ${ }^{9}$.

\section{Endovenous Laser Ablation (EVLA)}

EVLA, similar to RFA, causes the burning of the saphenous vein to achieve clinical results. Nerve and skin can be collaterally injured by 
the thermal energy. And also similar to RFA, the nervous damage data are quite different due to study design and laser parameters used.

The wavelengths provide power from 10 to 15 watts and lead to $20-140 \mathrm{~J} / \mathrm{cm}$ linear endovenous energy density (LEED) in the vein lumen. This amount of energy density is sufficient for vein wall heating and the formation of fibrosis ${ }^{35}$.

A prospective nonrandomized single-center cohort study using a $1470 \mathrm{~nm}$ wavelength laser with bare-tip fiber reported 3.9\% paresthesia ${ }^{36}$. Similar to these statistics, but with different design studies, Gifford et al. described paraesthesia after treating the whole GSV with EVLA/RFA in $4 \%{ }^{37}$ and Dermody et $a l^{33}$ showed that EVLA had a $3.8 \%$ incidence of paresthesia.

In each one of these articles, no data is available to evaluate long term symptoms. With longer follow-up, a 2011 publication using EVLA of GSV with a $1470 \mathrm{~nm}$ diode radial fiber laser showed that local paresthesia occurred in four patients $(8 \%)$ at 30 days with average paresthesia area of $47 \mathrm{~cm} 2$. After six months, paresthesia disappeared in one patient. In the other patients $(6 \%)$, the paresthesia area reduced to $24 \mathrm{~cm}^{238}$.

EVLA of the SSV seems to be a safe modality with excellent short-term results but temporary paresthesia of $6 \%{ }^{39}$. Boersma et al. evaluated 28 studies of laser treatment on 2950 limbs and found postoperative paresthesia in $4.8 \%$ (EVLA) of the cases ${ }^{25}$.

Transient paresthesia was seen even in EVLA of insufficient perforating veins and despite careful administration of tumescent anesthesia; in two patients of 124 total according to Boersma et a $\mathrm{t}^{40}$ and two patients in a total of 13 treated in Dumantepe's publication ${ }^{41}$.

\section{Cryosurgery}

Cryosurgery for varicose veins was introduced in 1978 and first clinically applied in 1982. It works by the passage of nitrogen oxide (N2O) through a very small nozzle under very high pressure, which decompresses and lowers the temperature of the probe to $-85^{\circ} \mathrm{C}$ in only a few seconds. During freezing, an ice ball forms at the tip of the probe, adhering the vein to the tip. Removal of the vein is obtained by withdrawing the probe in the direction of the entrance. A retrospective noncomparative study with a total of 84 patients (131 limbs) with varicose veins with GSV incompetence was treated with cryosurgery over a 2 year period showed cutaneous nerve damage - defined as numbness and paresthesia - in $3 \operatorname{limbs}(2.3 \%)^{42}$.

\section{High Intensity Focused Ultrasound (HIFU)}

More recently the use of high intensity focused ultrasound (HIFU) has been proposed to treat venous insufficiency. HIFU heats the vein at a temperature about $95-90^{\circ} \mathrm{C}$. Obermayer treated varicose veins and reported 4 legs out of 50 with dysesthesias suggesting damage to nerves.

No deep vein thrombosis, pulmonary embolism or arterial damage was reported in the initial cases ${ }^{43}$. The focused ultrasound has been shown to damage arterial structures neighboring the treated vessel and the initial clinical data demonstrate that nerves are probably affected in the treated region ${ }^{44}$.

\section{Preventing nerve damage}

\section{Techniques}

Sclerotherapy procedures and low volume of the sclerosant are possible ways to prevent complications.

When performing an EVLT a radial fiber is preferable to bare tip fiber, as the latter causes more nerve damages as shown in a comparative study ${ }^{35}$.

The lower is the energy level used the less nerve damage will occur, as Rathod has shown that a higher linear endovenous energy density increased significantly the incidence of paresthesia ${ }^{45}$. Although, the decrease of energy should not jeopardize the long-term occlusion of the vein.

Another important factor is the infiltration with perivenous tumescent anesthesia, as it helps to dissipate the heat generated by EVLA/RFA ${ }^{46}$.

Regarding the site of endovenous access, studies comparing puncture sites are small and do not allow us to make important conclusions. A small study showed less nerve damage in SSV after midcalf puncture as compared to distal puncture ${ }^{47}$. Another small study did not find significant differences between mid-calf access and distal access to treat the $\mathrm{GSV}^{48}$

\section{Local Anesthesia Methods}

The incidence of nerve damage is decreased when the technique is more conservative and less aggressive, using only local anesthesia to the skin. Conservative surgery such as CHIVA (Conservatrice Hémodynamique de l'Insuffisance Veineuse en Ambulatoire / ambulatory conservative hemodynamic treatment venous insufficiency) ${ }^{49}$, Muller Phlebectomy and ASVAL (ablation under local anesthesia) ${ }^{50}$ added a new perspective for eliminating reflux, sparing the main saphenous trunks with fewer nerve injuries. Also, the patient warns the doctor if a nerve is touched and it makes it hard to cause injury ${ }^{51}$.

The CHIVA technique has a near-zero incidence of nerve damage with significantly less damage than stripping in randomized clinical trials $^{49,52}$. The ASVAL technique also has a low incidence of nerve damage, supposedly for the same reasons considered before ${ }^{50}$.

\section{Recurrence}

Recurrences might be a problem with the partial stripping strategy. Jones et $a l^{30}$ showed that recurrence was greater in patients stripped to the knee level (43\%) as compared to patients with complete stripping (25\%). But the most common cause of recurrence was the neovascularisation rather than the saphenous remnant.

Obviously, treating recurrence of the GSV has higher complications rates due to scar and fibrosis.

Van Groenendael et al. showed a large occurrence of temporary paraesthesia in $13 \%$ of these patients ${ }^{53}$. Recently, these cases have been treated by foam sclerotherapy with good results ${ }^{54}$. However further studies are welcome to clear this indication since thrombophlebitis and recurrence are common problems with foam sclerotherapy.

\section{Anatomy and ultrasound}

The knowledge about nerve anatomy is pivotal to avoid such complications but it is not a guarantee that lesions will not occur, as pointed out by Sam et al, nerve damage can happen with the best 
surgeons ${ }^{4}$. Figures 5 and 6 address the "risky points", where nerves and veins are close and most lesions occur.

Finally, ultrasound is increasingly becoming essential for the vascular surgeon for surgical planning. Nerve anatomy of the lower limb is extremely variable.

A publication found a relationship in anatomical variation between SN and GSV; in 54 cases, the nerve was posterior to the vein and anterior in 32 cases $^{15}$. Ricci et al identified contact points between NSu and SPV ("risk points") in 39 of 40 members (97\%) studied ${ }^{5}$. The use of ultrasound, especially performed by the surgical team, identifies points of possible injury ("risk points" - Fig 5 and 6) and avoid nerve damage during VV surgery.

\section{Possible treatments after nerve injury}

Nerve injury pattern is well documented on clinical examination, electromyogram, magnetic resonance imaging and surgical pathology ${ }^{9}$. The vast majority of nerves damaged in varicose vein operations are only sensitive and do not require treatment.

Transient changes in nerve transmission observed weeks after surgery can be due to the temporary neuropraxia caused by edema, hematoma, inflammatory processes, or simply by the mechanical irritation during operation ${ }^{55}$.

After an injury to nerves is detected, it is recommended to wait 4 to 6 weeks for the appearance of clinical signs of motor recovery indicating neuropraxia.

If motor recovery does not occur within this period, exploratory surgery of the nerve should then be performed. Intraoperative findings will determine the technique to be used (neurolysis, neurorrhaphy, or nerve grafting) ${ }^{10}$.

Peroneal nerve damage, femoral and sciatic may cause great disability and the possibility of nerve reconstruction should be considered in patients not responding to clinical therapy ${ }^{56}$.

\section{Malpractice Claims after varicose vein surgery}

Campbell et $a l^{3}$ showed that nerve damage is the most common reason for malpractice claims after venous procedures, accounting for $31 \%$ of the claims. A review concerning nerve damage after varicose veins operation found that between $4 \%$ and $23 \%$ of patients remain with sensory loss after the procedure, depending on the testing method and study ${ }^{4}$.

The same review showed that nearly all treatment methods cause nerve damages. Phlebectomies, stripping, radiofrequency and endolaser present nerve damages and studies vary greatly concerning incidence of this complication (from $0 \%$ to $33 \%)^{4}$.
Nerve lesions were the cause of malpractice claims in 62 out of 200 claims $^{57}$. A review of 200 consecutive lawsuits on venous operations found that the lesion was on the saphenous nerve in 8 patients, the sural nerve in 15 patients, the peroneal nerve in 18 patients and cutaneous nerve in 21 cases.

Claims due to improper communication and inadequate medical record keeping are also frequent58. Although it seems obvious, good anatomical knowledge, proper preoperative planning, clear communication, safe operation protocols and good clinical records are important to prevent claims. The preoperative duplex scan should be performed by the surgical team or at least well communicated to the surgeon, and it is pivotal ${ }^{58}$.

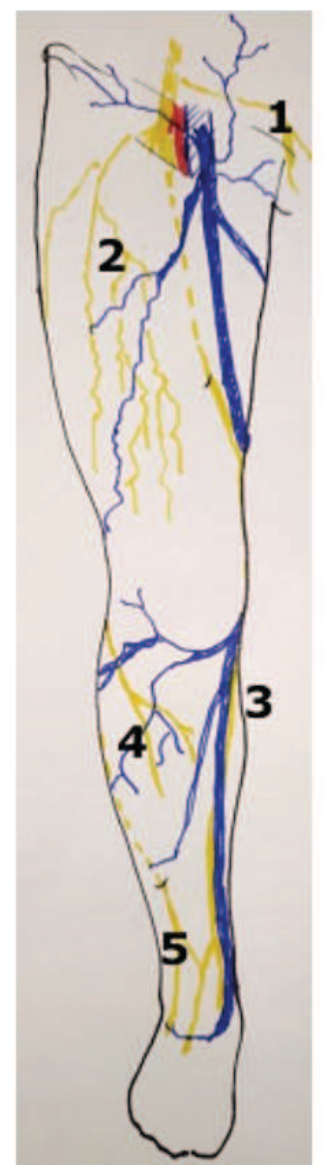

Fig 5 - "Risk points". 1) Ilioinguinal nerve at risk during initial groin dissection. 2) Femoral-cutaneous nerves at risk when anterior accessory saphenous vein or veins in the anterior region of the thigh are committed. 3) Relationship between the great saphenous vein and nerve. 4) Lateral cutaneous nerve (common fibular nerve) can be damaged in varicose vein dissection in the lateral compartment of the leg. 5) Superficial fibular nerve can be damaged during dissection in local varices.

Claims due to nerve injury are frequently settled after accepting liability. This is due to the fact that this 
complication may cause permanent disability even when instantly repaired ${ }^{59}$.

A study about litigation claims after vascular surgery showed that nerve damage is responsible for nearly a third of the successful malpractice claims in the courts after venous operations. This British study showed a $61 \%$ success rate of malpractice claims in varicose veins operations ${ }^{60}$. The mean compensation for damage was $100.000 €$ and some cases received higher sums.

No matter how simple a procedure may appear, all operations carry risks for the patient. Therefore, knowledge about adverse events is essential for providing patients with accurate advice and information regarding the potential risks and benefits of treatment options ${ }^{2}$.

Endovenous techniques will still be affected by claims of recurrence, unsatisfactory outcome/poor cosmetic result, pigmentation, and scarring. Patients' expectations will be higher with endovenous techniques, which are being marketed as less invasive than surgery. Patients undergoing varicose vein treatment/surgery must be made aware of these risks and this discussion needs to be clearly recorded in the patient's records and/or consent form, along with the receipt of a supporting patient information "sheet" 46 . There are no current articles on litigation in modern techniques for treating varicose veins.

The patient's choice now seems to be a clinical priority and most practitioners agree that at least one alternative to conventional surgery should be available. Not all patients may be suitable for all modalities, and selection criteria differ according to Doppler ultrasound and clinical findings and chosen method ${ }^{17}$. We should not forget that elastic stockings and venoactive drugs are possible alternatives for most varicose vein procedures and patients should be aware of this possibility ${ }^{61}$.

\section{Conclusion}

Chronic venous insufficiency is a high prevalence disease and nerve damage is the most common reason for malpractice claims after venous procedures. Nerve damage during varicose vein procedures should always be kept in mind; even good surgeons can cause nerve damage.

Anatomical knowledge, team experience and respecting the characteristics of every procedure are pivotal for minimizing the risk of nerve damage.

Some techniques may present more nerve damage than others ${ }^{4}$ and both the choice of the type of procedure and strategies to prevent such lesion with every technique are advisable. For example, partial stripping/ablation instead of total saphenous stripping may reduce its incidence ${ }^{4}$.

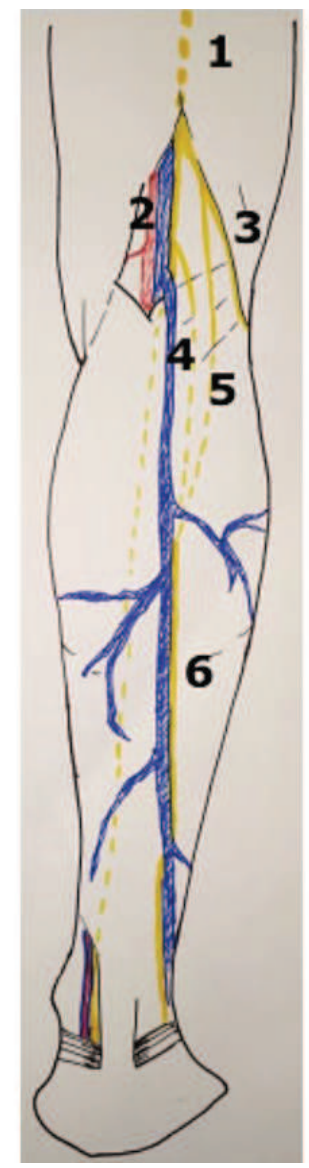

Fig 6 - "Risk points". 1) Sciatic nerve and sciatic varices are related. 2) Tibial nerve is not usually damaged during varicose vein surgery but can suffer thermal lesion. 4, 5 e 6) relationship between the medial and lateral sural cutaneous nerve, sural nerve and the small saphenous veins.

The type of anesthesia is also an important factor because if the patient is responsive and the nerve is not blocked, the patient can tell the surgeon if the nerve is touched. The use of ultrasound before the procedure by the surgeon himself, with localization of nerves and "risky points", could reduce the incidence of nerve lesions. Highresolution US permits visualization of peripheral nerves prior to the intervention ${ }^{5}$.

In order to minimize nerve damage, the authors usually perform same-day preoperative ultrasound and operation under local anesthesia in all patients. The ultrasound considers vein reflux and anatomy and nerves related to these veins. We prefer saphenous sparing procedures that further minimize nerve damage. All patients are offered elastic stocking as an alternative treatment and full informed consent is signed by all patients (in which the nerve damage possibility is disclosed).

If damage happens, identification should be prompt and treatment fast in order to obtain good results, mainly in cases involving motor disability. 


\section{References}

1) Evans CJ, Allan PL, Lee AJ, Bradbury AW, Ruckley CV, Fowkes FG. Prevalence of venous reflux in the general population on duplex scanning: the Edinburgh vein study. J Vasc Surg [Internet]. 1998 Nov;28(5):767-76. Available from: https://doi.org/10.1016/ $\underline{\mathrm{s} 0741-5214(98) 70051-5}$

2) Rudström H, Bergqvist D, Ahlberg J, Björck M. Insurance claims after vascular surgery in Sweden. Eur J Vasc Endovasc Surg [Internet]. 2011 Oct;42(4):498-505. Available from: https:// doi.org/10.1016/j.ejvs.2011.04.026

3) Campbell WB, France F, Goodwin HM, Research and Audit Committee of the Vascular Surgical Society of Great Britain and Ireland. Medicolegal claims in vascular surgery. Ann R Coll Surg Engl [Internet]. 2002 May;84(3):181-4. Available from: https:// www.ncbi.nlm.nih.gov/pubmed/12092871

4) Sam RC, Silverman SH, Bradbury AW. Nerve Injuries and Varicose Vein Surgery. Eur J Vasc Endovasc Surg [Internet]. 2004 Feb 1;27(2):113-20. Available from: https://doi.org/10.1016/ j.ejvs.2003.11.007

5) Ricci S, Moro L, Antonelli Incalzi R. Ultrasound imaging of the sural nerve: ultrasound anatomy and rationale for investigation. Eur J Vasc Endovasc Surg [Internet]. 2010 May;39(5):636-41. Available from: https://doi.org/10.1016/j.ejvs.2009.11.024

6) Seddon HJ. Three types of nerve injury. Brain [Internet]. 1943; Available from: https://academic.oup.com/brain/ article-abstract/66/4/237/323776

7) Sunderland S. TRAUMATIC INJURIES OF PERIPHERAL NERVES: I.-SIMPLE COMPRESSION INJURIES OF THE RADIAL NERVE. Brain [Internet]. 1945; Available from: https:// academic.oup.com/brain/article-abstract/68/1/56/470730

8) Ricci S. Ultrasound observation of the sciatic nerve and its branches at the popliteal fossa: always visible, never seen. Eur J Vasc Endovasc Surg [Internet]. 2005 Dec;30(6):659-63. Available from: https://doi.org/10.1016/j.ejvs.2005.06.004

9) Shahid KR, Dellon AL, Amrami KK, Spinner RJ. Sciatic and peroneal nerve injuries after endovascular ablation of lower extremity varicosities: case reports and review of the literature. Ann Plast Surg [Internet]. 2015 Jan;74(1):64-8. Available from: https:// doi.org/10.1097/SAP.0000000000000193

10) de Alvarenga Yoshida R, Yoshida WB, Sardenberg T, Sobreira ML, Rollo HA, Moura R. Fibular Nerve Injury After Small Saphenous Vein Surgery. Ann Vasc Surg [Internet]. 2012 Jul 1;26(5):729.e11-729.e15. Available from: https://doi.org/10.1016/ j.avsg.2011.11.042

11) Scurr JRH, Scurr JH. Common peroneal nerve injury during varicose vein surgery. Eur J Vasc Endovasc Surg [Internet]. 2006 Sep;32(3):334-5. Available from: https://doi.org/10.1016/ j.ejvs.2006.04.028

12) Ginanneschi F, Filippou G, Frediani B, Rossi A. Injury of cutaneous branches of the femoral nerve following varicose vein surgery. Acta Neurol Belg [Internet]. 2013 Sep;113(3):355-6. Available from: https://doi.org/10.1007/s13760-012-0173-3

13) Moawad MR, Masannat YA, Alhamdani A, Gibbons CP. Nerve injury in lower limb vascular surgery. Surgeon [Internet]. 2008 Feb;6(1):32-5. Available from: https://www.ncbi.nlm.nih.gov/ pubmed/18318086
14) Ghosh A, Chaudhury S. Morphology of saphenous nerve in cadavers: a guide to saphenous block and surgical interventions. Anat Cell Biol [Internet]. 2019 Sep;52(3):262-8. Available from: https:// doi.org/10.5115/acb.19.031

15) Veverková L, Jedlicka V, Vlcek P, Kalac J. The anatomical relationship between the saphenous nerve and the great saphenous vein. Phlebology [Internet]. 2011 Apr;26(3):114-8. Available from: https:// doi.org/10.1258/phleb.2010.010011

16) Gascoigne AC, Ian Taylor G, Corlett RJ, Briggs C, Ashton MW. The Relationship of Superficial Cutaneous Nerves and Interperforator Connections in the Leg: A Cadaveric Anatomical Study. Plast Reconstr Surg [Internet]. 2017 Apr;139(4):994e - 1002e. Available from: https://doi.org/10.1097/PRS.0000000000003157

17) McBride KD. Changing to endovenous treatment for varicose veins: how much more evidence is needed? Surgeon [Internet]. 2011 Jun;9(3):150-9. Available from: https:// doi.org/10.1016/j.surge.2010.11.002

18) Schweighofer G, Mühlberger D, Brenner E. The anatomy of the small saphenous vein: fascial and neural relations, saphenofemoral junction, and valves. J Vasc Surg [Internet]. 2010 Apr;51(4):982-9. Available from: https://doi.org/10.1016/j.jvs.2009.08.094

19) Fernández CF, Roizental M, Carvallo J. Combined endovenous laser therapy and microphlebectomy in the treatment of varicose veins: Efficacy and complications of a large single-center experience. J Vasc Surg [Internet]. 2008 Oct;48(4):947-52. Available from: https://doi.org/10.1016/j.jvs.2008.05.029

20) Cavezzi A, Parsi K. Complications of foam sclerotherapy. Phlebology [Internet]. 2012 Mar;27 Suppl 1:46-51. Available from: https://doi.org/10.1258/phleb.2012.012s09

21) Hill D. Nerve Injury Associated with Sclerotherapy. Phlebologie. 2010;63(3):55-7.

22) Wood JJ, Chant H, Laugharne M, Chant T, Mitchell DC. A prospective study of cutaneous nerve injury following long saphenous vein surgery. Eur J Vasc Endovasc Surg [Internet]. 2005 Dec;30(6):654-8. Available from: https://doi.org/10.1016/ j.ejvs.2005.06.009

23) Morrison C, Dalsing MC. Signs and symptoms of saphenous nerve injury after greater saphenous vein stripping: prevalence, severity, and relevance for modern practice. J Vasc Surg [Internet]. 2003 Nov 1;38(5):886-90. Available from: https://doi.org/10.1016/ $\underline{\mathrm{S} 0741-5214(03) 00790-0}$

24) Ahmed MS, Lutze S, Tembulatow M, Daeschlein G, Jünger M, Arnold A. Long-term outcome of open surgery in CVI patients concerning postoperative complications, perioperative hemodynamics and clinical efficacy, Part I. Clin Hemorheol Microcirc [Internet]. 2018;70(4):399-411. Available from: https:// doi.org/10.3233/CH-189305

25) Boersma D, Kornmann VNN, van Eekeren RRJP, Tromp E, Ünlü Ç, Reijnen MMJP, et al. Treatment Modalities for Small Saphenous Vein Insufficiency: Systematic Review and Meta-analysis. J Endovasc Ther [Internet]. 2016 Feb;23(1):199-211. Available from: https://doi.org/10.1177/1526602815616375

26) L Stotter ISAB. Comparative outcomes of radiofrequency endoluminal ablation, invagination stripping, and cryostripping in the treatment of great saphenous vein insufficiency. Phlebology 
[Internet]. 2006 Jun 1;21(2):60-4. Available from: https:// doi.org/10.1258/026835506777304692

27) Papakostas JC, Douitsis E, Sarmas I, Avgos S, Kyritsis A, Matsagkas M. The impact of direction of great saphenous vein total stripping on saphenous nerve injury. Phlebology [Internet]. 2014 Feb;29(1):52-7. Available from: https://doi.org/10.1258/ phleb.2012.012061

28) Holme JB, Skajaa K, Holme K. Incidence of lesions of the saphenous nerve after partial or complete stripping of the long saphenous vein. Acta Chir Scand [Internet]. 1990 Feb;156(2):145-8. Available from: https://www.ncbi.nlm.nih.gov/pubmed/2184634

29) Holme K, Matzen M, Bomberg AJ, Outzen SL, Holme JB Partial or total stripping of the great saphenous vein. 5-year recurrence frequency and 3-year frequency of neural complications after partial and total stripping of the great saphenous vein. Ugeskr Laeger [Internet]. 1996;158(4):405-8. Available from: https://europepmc.org/ abstract $/ \mathrm{med} / 8638298$

30) Jones L, Braithwaite BD, Selwyn D, Cooke S, Earnshaw JJ. Neovascularisation is the principal cause of varicose vein recurrence: results of a randomised trial of stripping the long saphenous vein. Eur J Vasc Endovasc Surg [Internet]. 1996 Nov;12(4):442-5. Available from: https://www.ncbi.nlm.nih.gov/pubmed/8980434

31) Hirsch $T$. Varicose vein therapy and nerve lesions. Vasa [Internet]. 2017 Mar;46(2):96-100. Available from: https:// doi.org/10.1024/0301-1526/a000588

32) Dzieciuchowicz L, Krasi\#ski Z, Gabriel M, Espinosa G. A prospective comparison of four methods of endovenous thermal ablation. Pol Przegl Chir [Internet]. 2011 Nov;83(11):597-605. Available from: https://doi.org/10.2478/v10035-011-0095-4

33) Dermody M, O'Donnell TF, Balk EM. Complications of endovenous ablation in randomized controlled trials. J Vasc Surg Venous Lymphat Disord [Internet]. 2013 Oct;1(4):427-36.e1. Available from: https://doi.org/10.1016/j.jvsv.2013.04.007

34) Park HS, Kwon Y, Eom BW, Lee T. Prospective nonrandomized comparison of quality of life and recurrence between high ligation and stripping and radiofrequency ablation for varicose veins. J Korean Surg Soc [Internet]. 2013 Jan;84(1):48-56. Available from: https://doi.org/10.4174/jkss.2013.84.1.48

35) Arslan Ü, Çal\#k E, Tort M, Y\#ld\#z Z, Tekin A\#, Limandal HK, et al. More Successful Results with Less Energy in Endovenous Laser Ablation Treatment: Long-term Comparison of Bare-tip Fiber $980 \mathrm{~nm}$ Laser and Radial-tip Fiber $1470 \mathrm{~nm}$ Laser Application. Ann Vasc Surg [Internet]. 2017 Nov;45:166-72. Available from: https:// doi.org/10.1016/j.avsg.2017.06.042

36) Steyaert A, De Letter J, Lanckneus M, Reusens H. Endovenous Laser Ablation of the Great Saphenous Vein with a 1470 $\mathrm{nm}$ Wavelength Laser : Results of a Prospective, Single Centre Cohort Study. Acta Chir Belg [Internet]. 2014 Jul;114(4):256-60. Available from: https://www.ncbi.nlm.nih.gov/pubmed/26021421

37) Gifford SM, Kalra M, Gloviczki P, Duncan AA, Oderich GS, Fleming MD, et al. Reflux in the below-knee great saphenous vein can be safely treated with endovenous ablation. J Vasc Surg Venous Lymphat Disord [Internet]. 2014 Oct;2(4):397-402. Available from: https://doi.org/10.1016/j.jvsv.2014.04.004

38) Pannier F, Rabe E, Rits J, Kadiss A, Maurins U. Endovenous laser ablation of great saphenous veins using a 1470 $\mathrm{nm}$ diode laser and the radial fibre--follow-up after six months.
Phlebology [Internet]. 2011 Feb;26(1):35-9. Available from: https:// doi.org/10.1258/phleb.2010.009096

39) Trip-Hoving M, Verheul JC, van Sterkenburg SMM, de Vries WR, Reijnen MMPJ. Endovenous laser therapy of the small saphenous vein: patient satisfaction and short-term results. Photomed Laser Surg [Internet]. 2009 Aug;27(4):655-8. Available from: https:// doi.org/10.1089/pho.2008.2389

40) Boersma D, Smulders DLJ, Bakker OJ, van den Haak RFF, Verhoeven BAN, Koning OHJ. Endovenous laser ablation of insufficient perforating veins: Energy is key to success. Vascular [Internet]. 2016 Apr;24(2):144-9. Available from: https:// doi.org/10.1177/1708538115587214

41) Dumantepe M, Tarhan A, Yurdakul I, Ozler A. Endovenous laser ablation of incompetent perforating veins with $1470 \mathrm{~nm}, 400 \mu \mathrm{m}$ radial fiber. Photomed Laser Surg [Internet]. 2012 Nov;30(11):672-7. Available from: https://doi.org/10.1089/pho.2012.3351

42) Kim KY, Kim JW. Early experience of transilluminated cryosurgery for varicose vein with saphenofemoral reflux: review of 84 patients (131 limbs). Ann Surg Treat Res [Internet]. 2017 Aug;93(2):98-102. Available from: https://doi.org/10.4174/ astr.2017.93.2.98

43) Obermayer A. Ultrasound-Guided High-Intensity Focused Ultrasound Extracorporeal Treatment of Superficial Lower Limb Veins: Preliminary Results and Method Description. Journal of Vascular Surgery: Venous and Lymphatic Disorders [Internet]. 2018;6(4):556-7. Available from: https://www.jvsvenous.org/action/showCitFormats? pii $=$ S2213-333X\%2818\%2930168-9\&

doi=10.1016\%2Fj.jvsv.2018.05.007

44) Faccini FP, Souza JMC, Arendt AL. Occlusion of the popliteal artery after focused ultrasound treatment - a case report. JTAVR [Internet]. 2018;3(1):37-40. Available from: https:// doi.org/10.24019/jtavr.65

45) Rathod J, Taori K, Joshi M, Mundhada R, Rewatkar A, Dhomane S, et al. Outcomes using a 1470-nm laser for symptomatic varicose veins. J Vasc Interv Radiol [Internet]. 2010 Dec;21(12):183540. Available from: https://doi.org/10.1016/j.jvir.2010.09.009

46) Scurr JRH, Scurr JH. Endovenous ablation of varicose veins: medicolegal claims will continue! Phlebology [Internet]. 2007;22(3):95-7. Available from: https:// doi.org/10.1258/026835507780807266

47) Doganci S, Yildirim V, Demirkilic U. Does puncture site affect the rate of nerve injuries following endovenous laser ablation of the small saphenous veins? Eur J Vasc Endovasc Surg [Internet]. 2011 Mar;41(3):400-5. Available from: https:// doi.org/10.1016/j.ejvs.2010.11.029

48) Samuel N, Wallace T, Carradice D, Shahin Y, Mazari FAK, Chetter IC. Endovenous laser ablation in the treatment of small saphenous varicose veins: does site of access influence early outcomes? Vasc Endovascular Surg [Internet]. 2012 May;46(4):310-4. Available from: https://doi.org/10.1177/1538574412443316

49) Bellmunt-Montoya S, Escribano JM, Dilme J, MartinezZapata MJ. CHIVA method for the treatment of chronic venous insufficiency. Cochrane Database Syst Rev [Internet]. 2015;(6). Available from: https://www.cochranelibrary.com/cdsr/ doi/10.1002/14651858.CD009648.pub3/abstract

50) Pittaluga $P$, Chastanet $S$. Treatment of varicose veins by ASVAL: results at 10 years. Ann Vasc Surg [Internet]. 2017;38:e10. Available from: https://doi.org/10.1016/j.avsg.2016.07.021 
51) Faccini FP, Ermini S, Franceschi C. CHIVA to treat saphenous vein insufficiency in chronic venous disease: characteristics and results. J vasc bras [Internet]. 2019 [cited 2019 Mar 15];18. Available from: http://www.scielo.br/scielo.php?script=sci arttext\& pid $=$ S1677-54492019000100401\& lng=en\& tlng=en

52) Parés JO, Juan J, Tellez R, Mata A, Moreno C, Quer FX, et al. Varicose vein surgery: stripping versus the CHIVA method: a randomized controlled trial. Ann Surg [Internet]. 2010 Apr;251(4):62431. Available from: https://doi.org/10.1097/SLA.0b013e3181d0d0a3

53) van Groenendael L, van der Vliet JA, Flinkenflögel L, Roovers EA, van Sterkenburg SMM, Reijnen MMPJ. Treatment of recurrent varicose veins of the great saphenous vein by conventional surgery and endovenous laser ablation. J Vasc Surg [Internet]. 2009 Nov;50(5):1106-13. Available from: https://doi.org/10.1016/ j.jvs.2009.06.057

54) Pavei P, Ferrini M, Spreafico G. Ultrasound guided foam sclerotherapy of recurrent varices of the great and small saphenous vein: 5-year follow up. Veins and [Internet]. 2014; Available from: http:// pagepressjournals.org/index.php/vl/article/view/vl.2014.4655

55) Jaworucka-Kaczorowska A, Oszkinis G, Huber J, WiertelKrawczuk A, Gabor E, Kaczorowski P. Saphenous vein stripping surgical technique and frequency of saphenous nerve injury. Phlebology [Internet]. 2015 Apr;30(3):210-6. Available from: https:// doi.org/10.1177/0268355514539316

56) Carp S. Peripheral Nerve Injury An Anatomical and Physiological Approach for Physical Therapy Intervention [Internet].
F.A. Davis; 2015. 384 p. Available from: https://market.android.com/ details?id=book-v-5vCAAAQBAJ

57) Scurr JRH, Scurr JH. Varicose veins: a review of 200 consecutive medicolegal claims. Clin Risk [Internet]. 2005 Nov 1;11(6):225-30. Available from: https:// doi.org/10.1258/135626205774560182

58) Faccini FP, Arendt AL, Pereira RQ, Oliveira AR de. CHIVA to spare the small and great saphenous veins after wrong-site surgery on a normal saphenous vein: a case report. J vasc bras [Internet]. 2019 [cited 2019 Mar 15];18. Available from: http://www.scielo.br/ scielo.php?pid=S1677-54492019000100601\& script=sci_arttext

59) Dickhoff C, Cremers JEL, Legemate DA, Koelemay MJW. Medical liability insurance claims after treatment of varicose veins. Phlebology [Internet]. 2014 Jun;29(5):293-7. Available from: https:// doi.org/10.1177/0268355512474251

60) Markides GA, Subar D, Al-Khaffaf H. Litigation Claims in Vascular Surgery in the United Kingdom's NHS. J Vasc Surg [Internet]. 2008;48(4):1066. Available from: https://doi.org/10.1016/ j.jvs.2008.08.083

61) Rabe E, Partsch H, Hafner J, Lattimer C, Mosti G, Neumann $\mathrm{M}$, et al. Indications for medical compression stockings in venous and lymphatic disorders: An evidence-based consensus statement. Phlebology [Internet]. 2018 Apr;33(3):163-84. Available from: https:// doi.org/10.1177/0268355516689631 